\title{
Deposição de Fitomassa em Formações Secundárias na Floresta Atlântica do Paraná
}

\author{
Jonas Eduardo Bianchin ${ }^{1}$, Renato Marques ${ }^{1}$, Ricardo Miranda Britez ${ }^{2}$, \\ Robson Louiz Capretz ${ }^{3}$
}

${ }^{1}$ Programa de Pós-graduação em Engenharia Florestal, Universidade Federal do Paraná - UFPR, Curitiba/PR, Brasil ${ }^{2}$ Sociedade de Pesquisa em Vida Selvagem e Educação Ambiental - SPVS, Curitiba/PR, Brasil

${ }^{3}$ Fundação Grupo Boticário de Proteção à Natureza, Curitiba/PR, Brasil

\begin{abstract}
RESUMO
Este trabalho objetivou avaliar a deposição de serapilheira em três formações secundárias com diferentes idades na Floresta Ombrófila Densa Submontana no Paraná. A serapilheira anual produzida foi avaliada mensalmente por 25 coletores $\left(1 \mathrm{~m}^{2}\right)$ distribuídos sistematicamente em cada formação secundária ( 1 ha) e separada em frações (ramos, órgãos reprodutivos, miscelânea e folhas). Não houve diferença significativa entre as formações quanto à deposição anual de serapilheira, provavelmente devido às semelhanças entre elas com relação à estrutura da vegetação e às condições meteorológicas. A maior deposição de serapilheira total e frações ocorreu nos meses com maiores temperatura e precipitação. A fração folhas foi a mais representativa na serapilheira total em todas as formações, sendo que na floresta secundária menos desenvolvida (FS-1) houve contribuição de um menor número de espécies, quando comparada com a floresta secundária intermediária (FS-2) e a floresta secundária mais desenvolvida (FS-3).
\end{abstract}

Palavras-chave: Floresta Ombrófila Densa, serapilheira, sucessão florestal.

\section{Litterfall in Secondary Forests in the Brazilian Atlantic Forest of Paraná State}

\begin{abstract}
This research is focused in evaluating the litterfall in secondary forests of Dense Ombrophilous Submontane Forest in the coast of Paraná state. The annual litterfall produced was evaluated monthly by 25 collectors $\left(1 \mathrm{~m}^{2}\right)$, systematically distributed in each secondary formation ( $\left.1 \mathrm{ha}\right)$ and separated into fractions (twigs, reproductive organs, remains, and leaves). There was no significant difference between the secondary formations on the annual litterfall, probably due to the similarities they both have with respect to the structure of vegetation and meteorological conditions. The highest deposition of total litter and fractions occurred in the months of highest temperature and rainfall. The fraction leaves were the most representative of total litterfall in all formations, with the less evolved secondary forests (FS-1) contributing with fewer number of species, when compared with the intermediate and more evolved secondary forests (FS-2) and (FS-3), respectively.
\end{abstract}

Keywords: Brazilian Atlantic Forest, litterfall, forest succession. 


\section{INTRODUÇÃO}

As florestas tropicais são importantes não somente pela imensa biodiversidade que abrigam mas também pelas funções ecossistêmicas e serviços ambientais que provêm, como a manutenção da fertilidade do solo por meio da transferência de nutrientes das plantas via serapilheira (Cunha et al., 1993). Isso ocorre em função da liberação dos nutrientes durante a decomposição da serapilheira depositada sobre os solos florestais, os quais são reaproveitados pelas plantas (Pinto \& Marques, 2003). No caso das florestas tropicais, a serapilheira torna-se a principal fonte de nutrientes para o solo, sendo que sua decomposição e o reaproveitamento dos seus nutrientes pela vegetação ajudam a garantir a sustentabilidade desses ecossistemas (Vital et al., 2004; Calvi et al., 2009).

A serapilheira é a camada de material morto proveniente da biomassa aérea da vegetação, a qual permanece no solo até ser fragmentada e decomposta pelos processos físico-químicos e bióticos (Aduan et al., 2003). Inclui folhas, caules, ramos, frutos, flores e outras partes da planta que, uma vez depositadas, sofrem um processo de liberação eventual dos elementos minerais que compõem seus tecidos orgânicos (Golley et al., 1978), representando assim uma forma de entrada e posterior incremento de matéria orgânica ao solo (Barbosa \& Faria, 2006).

A Floresta Atlântica é extremamente fragmentada, sendo que atualmente mais de $80 \%$ de sua cobertura encontra-se em fragmentos menores do que 50 hectares, em diferentes estádios sucessionais (Ribeiro et al., 2009). Na análise da paisagem da Área de Proteção Ambiental (APA) de Guaraqueçaba, litoral do estado do Paraná, local deste estudo, Kauano et al. (2012) avaliaram que $83 \%$ da área total dessa Unidade de Conservação são dominados por florestas, dos quais 68,5\% pela fisionomia Floresta Ombrófila Densa, sendo que $9,5 \%$ referem-se a florestas secundárias.

Estudos sobre deposição de serapilheira em diferentes fases de sucessão na Floresta Atlântica são essenciais para o conhecimento do funcionamento ecossistêmico. Alguns trabalhos envolvendo deposição de serapilheira e ciclagem de nutrientes em sucessão secundária têm sido desenvolvidos no litoral do Paraná, nas diversas fitofisionomias da Floresta Ombrófila Densa (Pinto \& Marques, 2003; Scheer et al., 2009; Dickow et al., 2012).
No entanto, pesquisas com enfoque na dinâmica de deposição de serapilheira com o aumento da idade e da complexidade de estrutura da floresta são necessárias para se compreender o funcionamento desses ecossistemas, as quais podem fornecer importantes subsídios para o manejo adequado e a conservação dessas áreas.

Nesse mosaico de tipologias florestais, este trabalho visou caracterizar a deposição de serapilheira em três formações secundárias de Floresta Ombrófila Densa Submontana, no município de Antonina, litoral do Paraná. Esta avaliação pretendeu responder as seguintes perguntas: (1) Existem diferenças entre as florestas estudadas no que diz respeito aos totais depositados e à sazonalidade? (2) Existe correlação entre deposição e dados climáticos? (3) Qual a participação das principais espécies na deposição do componente folhas da serapilheira?

\section{MATERIAL E MÉTODOS}

\section{1. Área de estudo}

O estudo foi desenvolvido na Reserva Natural do Rio Cachoeira, município de Antonina, litoral do estado do Paraná, sul do Brasil (Figura 1). A reserva, que está inserida na APA de Guaraqueçaba, possui área de aproximadamente 8.600 ha e pertence à Sociedade de Pesquisa em Vida Selvagem e Educação Ambiental (SPVS). A área de estudo situa-se próxima às coordenadas $25^{\circ} 18^{\prime}$ Sul e $48^{\circ} 40^{\prime}$ Oeste, com altitude aproximada de 100 metros.

O clima na região é do tipo Cfa, segundo a classificação de Köppen (subtropical úmido mesotérmico). A temperatura média do mês mais quente é maior que $22^{\circ} \mathrm{C}$ e a temperatura média do mês mais frio varia entre $3{ }^{\circ} \mathrm{C}$ e $18^{\circ} \mathrm{C}$ (Figura 2). Por se tratarem de áreas com pouca altitude, em torno de $100 \mathrm{~m}$, as geadas são pouco frequentes. A precipitação é relativamente alta, favorecida pelas correntes quentes que trazem umidade do oceano para o continente, com valores anuais variando entre $2.000 \mathrm{~mm}$ e $3.000 \mathrm{~mm}$. Os maiores volumes de chuva ocorrem no verão, nos meses de dezembro a março. Na estação fria, apesar de a precipitação ser mais baixa, não há escassez de chuva (IPARDES, 2001).

As principais classes de solo encontradas nas reservas são Neossolos, Gleissolos, Cambissolos e Argissolos (Ferreti \& Britez, 2005). De acordo com a classificação dos solos realizado na reserva (dados não 


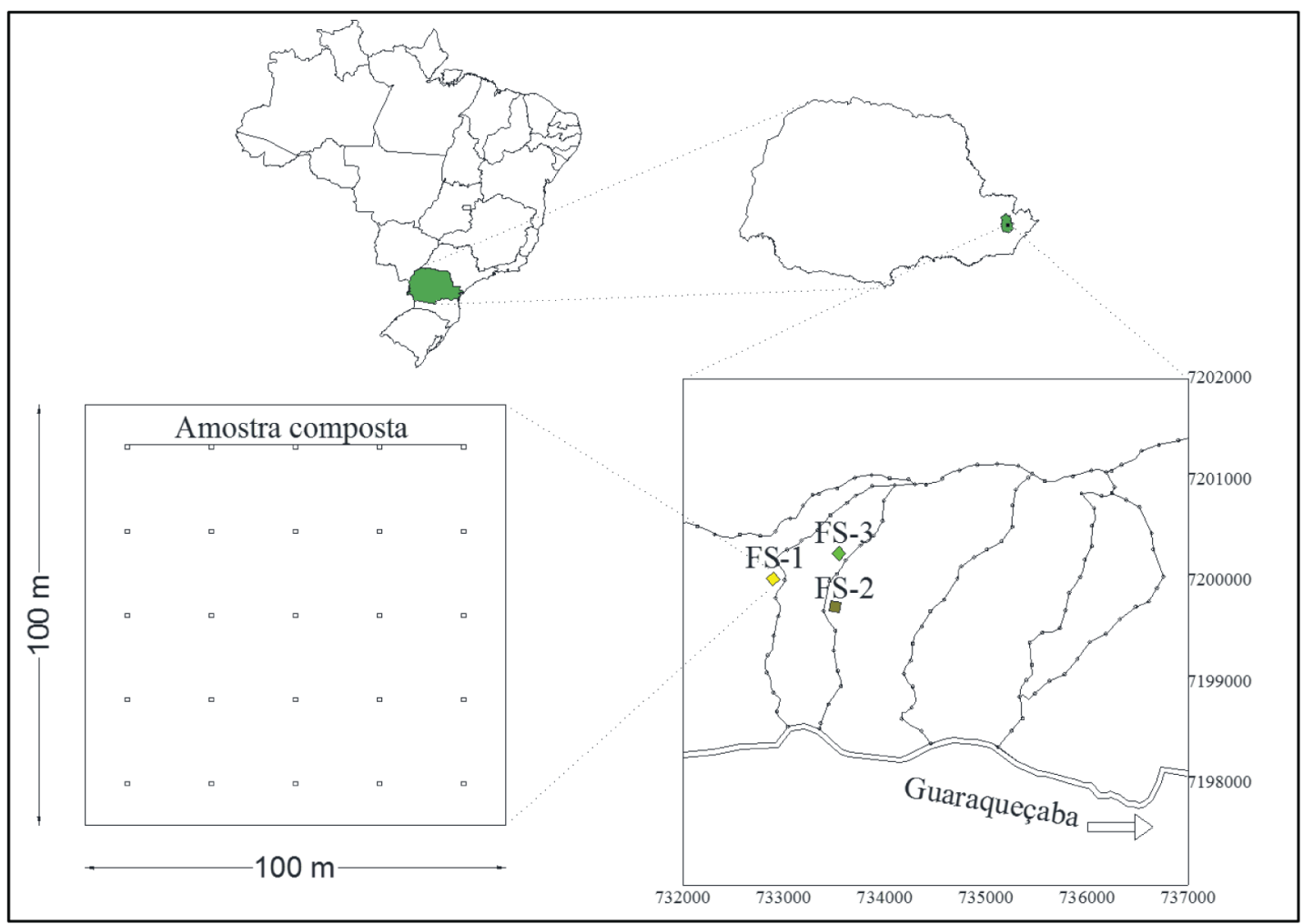

Figura 1. Área de estudo e distribuição espacial dos coletores de serapilheira nas parcelas. FS-1 = floresta secundária menos desenvolvida; FS-2 = floresta secundária intermediária; FS-3 = floresta secundária mais desenvolvida.

Figure 1. Study area and spatial distribution of litterfall collectors in the plots. FS-1 = less evolved secondary forest; FS-2 = intermediate secondary forests; FS-3 = more evolved secondary forest.

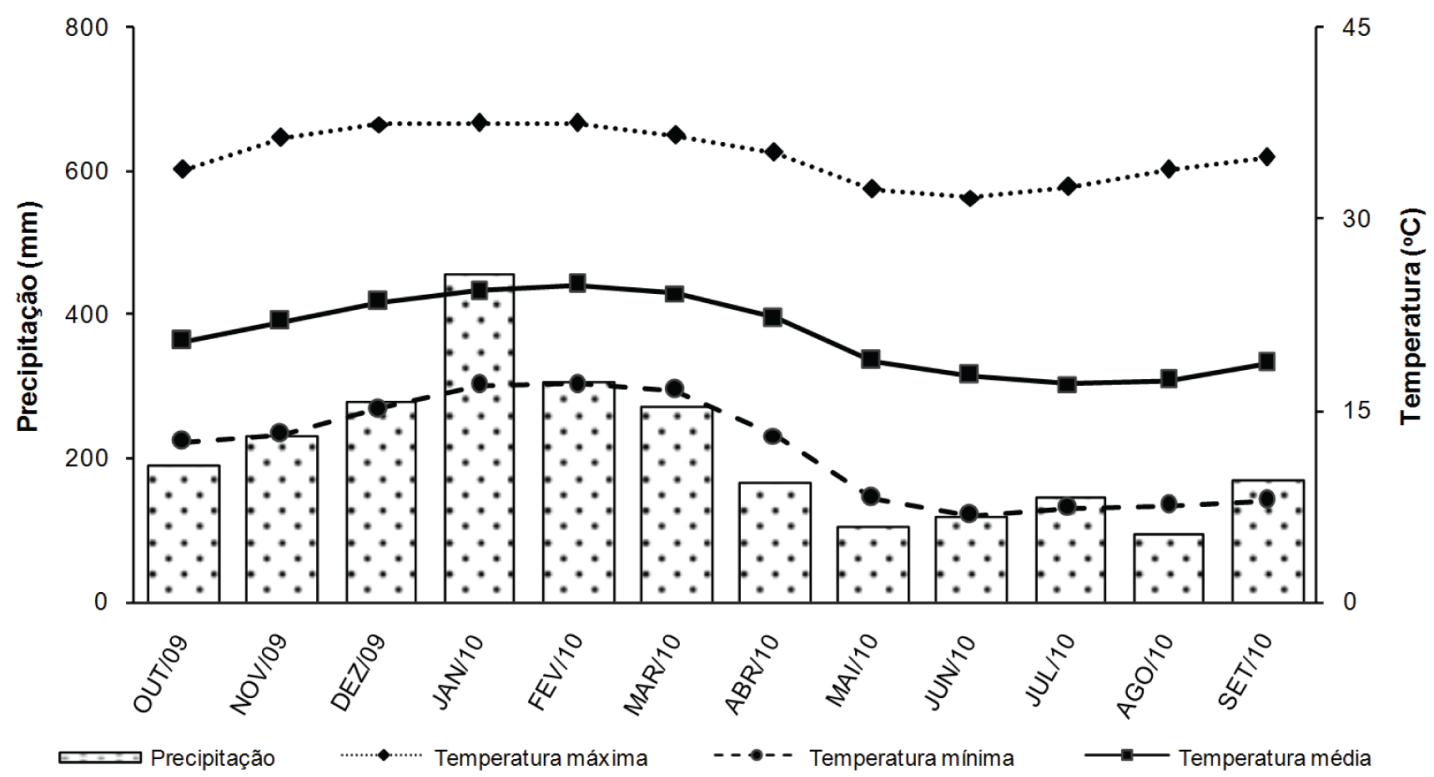

Figura 2. Dados meteorológicos de precipitação e temperatura da estação meteorológica do SIMEPAR, em Antonina, PR, referentes ao período de estudo.

Figure 2. Meteorological data of precipitation and temperature from the SIMEPAR weather station in Antonina $\mathrm{PR}$, referring to the study period. 
publicados), nas parcelas de estudo ocorrem solos da ordem Cambissolo. A vegetação da área de estudo é a Floresta Ombrófila Densa Submontana (IBGE, 2012), que compreende as florestas que ocupam o início das encostas da Serra do Mar, situadas entre aproximadamente 20 e 400 metros de altitude, com grande diversidade e riqueza de espécies (Roderjan et al., 2002).

Para o estudo da deposição de serapilheira, foram selecionadas três áreas de floresta secundária (de 1 ha cada uma) em diferentes estágios sucessionais: floresta secundária menos desenvolvida (FS-1); floresta secundária intermediária (FS-2); e floresta secundária mais desenvolvida (FS-3). Em FS-1, a comunidade arbórea, que sofreu corte raso há cerca de 50 anos, apresenta apenas um estrato, cuja densidade de indivíduos com diâmetro à altura do peito (DAP) maior que $10 \mathrm{~cm}$ é de 1.985 ind. ha ${ }^{-1}$, área basal de $30,4 \mathrm{~m}^{2} \mathrm{ha}^{-1}$ e na qual ocorrem 83 espécies, dentre as quais Pera glabrata (Schott) Poepp. ex Baill. e Vochysia bifalcata Warm. representam mais da metade da cobertura da área, seguidas de Tibouchina pulchra Cogn. A FS-2 caracteriza-se pela presença de dois estratos definidos, com densidade de 1.924 ind. ha ${ }^{-1}$, a área basal de 33,0 $\mathrm{m}^{2} \mathrm{ha}^{-1} \mathrm{e} 129$ espécies arbóreas. Já na FS-3, a densidade é de 1.764 ind. ha ${ }^{-1}$, a área basal, de $30,7 \mathrm{~m}^{2} \mathrm{ha}^{-1}$, com a presença de 128 espécies. Em FS-2 e FS-3, nas quais desde aproximadamente 80 anos não há intervenção humana (dados não publicados), as espécies dominantes são Hieronyma alchorneoides Allemão, Sloanea guianensis (Aubl.) Benth., Cupania oblongifolia Mart. e Vochysia bifalcata. A FS-3 apresenta sub-bosque mais desenvolvido em comparação a FS-2, com grande densidade de Rubiáceas, especialmente Psychotria mapourioides DC. e Psychotria nuda (Cham. e Schltdl.) Wawra.

\subsection{Coleta e processamento da serapilheira}

As coletas de serapilheira foram realizadas mensalmente entre outubro de 2009 e setembro de 2010, em FS-1, FS-2 e FS-3. Para tanto, foram utilizados coletores feitos de PVC, com $1 \mathrm{~m}^{2}$ de área e tela de nylon de $2 \mathrm{~mm}$, espacializados de forma uniforme, a fim de cobrir toda a parcela (Figura 1). Em cada coleta, a serapilheira foi recolhida dos coletores e acondicionada em sacos plásticos devidamente identificados e posteriormente processada no Laboratório de Biogeoquímica (LAB) da Universidade Federal do Paraná (UFPR).

No laboratório, as amostras foram separadas nas seguintes frações: folhas; ramos e galhos (diâmetro inferior a $2 \mathrm{~cm}$ ); órgãos reprodutivos (flores, frutos e sementes); e miscelânea. Nessa última fração foram incluídas todas as partículas de material depositadas que, durante o processo de triagem, não foram enquadradas em nenhuma das outras categorias, desde de fragmentos de folhas e ramos até restos de insetos. A fração folhas foi separada por espécie arbórea, quando possível, e aquelas não identificadas foram classificadas como folhas diversas. Após a triagem, o material foi acondicionado em sacos de papel e seco em estufa a $60 \pm 2{ }^{\circ} \mathrm{C}$ até atingir peso constante. Em seguida, o material foi pesado em balança de precisão de $0,02 \mathrm{~g}$ para obtenção da massa seca por fração.

A quantidade total de serapilheira aportada por hectare foi estimada utilizando-se a Equação 1, adaptada de Toledo \& Pereira (2004).

$P M S=\frac{\sum P S \times 10000}{A C \times n}$

em que: PMS = produção mensal de serapilheira, em $\mathrm{kg} \mathrm{ha}^{-1} ; \mathrm{PS}=$ produção de serapilheira de cada coletor, em $\mathrm{kg} ; \mathrm{AC}=$ área do coletor, $\mathrm{em} \mathrm{m}^{2} ; \mathrm{n}=$ número de coletores agrupados.

Os coletores (subamostras) foram agrupados formando amostras compostas de serapilheira (Figura 1), pelo fato de estarem alinhados e distribuídos sistematicamente. O agrupamento dos coletores acompanhou a declividade do terreno, a fim de tornar as amostras mais homogêneas, reduzindo a variabilidade.

\subsection{Análises estatísticas}

Os dados de quantidade de serapilheira depositada foram analisados no programa ASSISTAT (Silva \& Azevedo, 2002). Primeiramente foi testada a homogeneidade das variâncias dos tratamentos, utilizando-se o teste de Bartlett. Os tratamentos cujas variâncias não eram homogêneas foram transformados (raiz quadrada, logaritmo). Depois de verificada a normalidade, os dados foram submetidos à ANOVA e, em seguida, as médias foram comparadas entre si pelo teste de Tukey, com probabilidade de $95 \%$. Para verificar a influência das variáveis meteorológicas na deposição de serapilheira em cada área foi realizado o teste de correlação de Pearson entre os fatores (correlação linear simples). Para testar a significância dos coeficientes de correlação foi aplicado o teste t de Student, considerando as probabilidades $\mathrm{p}=0,05 \mathrm{e} \mathrm{p}=0,01$. 


\section{RESULTADOS E DISCUSSÃO}

A quantidade de serapilheira total depositada variou entre as formações secundárias (Tabela 1). A deposição total de serapilheira foi estatisticamente superior na FS-3 em comparação a FS-2, sendo que a FS-1 não diferiu das demais áreas. Apesar disso, as quantidades depositadas foram semelhantes, $o$ que pode ser explicado pela homogeneidade das condições climáticas vigentes nas áreas, em virtude da proximidade entre elas e também devido à similaridade das áreas quanto à estrutura da comunidade, uma vez que ambos os fatores influenciam fortemente a deposição de serapilheira arbórea (Dickow et al., 2012). Além disso, com o avanço da sucessão secundária, o padrão de deposição de serapilheira tende a se estabilizar (Pezzatto \& Wisniewski, 2006), como reflexo da estabilização da produtividade primária, uma vez que a produção de serapilheira apresenta correlação com a produtividade primária das florestas (Bray \& Gorham, 1964). Assim, em alguns casos, as florestas secundárias iniciais depositam maior quantidade de serapilheira que florestas maduras (Meguro et al., 1979).

Os valores de deposição de serapilheira no verão e na primavera foram significativamente maiores quando comparados com a do outono e a do inverno, em todas as áreas (Tabela 1). Resultados semelhantes foram encontrados por Pinto \& Marques (2003) em Florestal Atlântica no litoral do Paraná, por Calvi et al. (2009) em áreas secundárias de Floresta Atlântica no Espírito Santo e por Bertalot et al. (2004) para quatro espécies da família Fabaceae em um plantio em Botucatu, SP.

A deposição de serapilheira nas áreas foi contínua ao longo do ano (Figura 3), apresentando variação mensal entre $311 \mathrm{~kg} \mathrm{ha}^{-1}$ até $1.556 \mathrm{~kg} \mathrm{ha}^{-1}$. Foram identificados dois picos de deposição diferenciados: o primeiro

Tabela 1. Deposição anual de serapilheira total por estação do ano em três formações secundárias de Floresta Ombrófila Densa Submontana em Antonina, PR.

Table 1. Annual total litterfall by season in three secondary formations of the Dense Ombrophilous Submontane Forest in Antonina, PR.

\begin{tabular}{|c|c|c|c|c|c|c|c|c|c|c|}
\hline \multirow{3}{*}{ Área } & \multicolumn{2}{|c|}{ PRIMAVERA } & \multicolumn{2}{|c|}{ VERÃO } & \multicolumn{2}{|c|}{ OUTONO } & \multicolumn{2}{|c|}{ INVERNO } & \multicolumn{2}{|l|}{ TOTAL } \\
\hline & Deposição & $\mathrm{CV}$ & Deposição & $\mathrm{CV}$ & Deposição & $\mathrm{CV}$ & Deposição & $\mathrm{CV}$ & Deposição & $\mathrm{CV}$ \\
\hline & $\left(\mathrm{kg} \mathrm{ha}^{-1}\right)$ & $(\%)$ & $\left(\mathrm{kg} \mathrm{ha}^{-1}\right)$ & $(\%)$ & $\left(\mathrm{kg} \mathrm{ha}^{-1}\right)$ & $(\%)$ & $\left(\mathrm{kg} \mathrm{ha}^{-1}\right)$ & $(\%)$ & $\left(\mathrm{kgha}^{-1}\right.$ ano $\left.^{-1}\right)$ & $(\%)$ \\
\hline FS-1 & $2214,7 \mathrm{Ab}$ & 8,7 & $2503,8 \mathrm{Ab}$ & 11,3 & $1817,1 \mathrm{Ba}$ & 18,8 & $1186,3 \mathrm{Ca}$ & 13,3 & $7721,9 \mathrm{ab}$ & 9,0 \\
\hline FS-2 & 2420,7 Aab & 13,5 & $2412,6 \mathrm{Ab}$ & 8,4 & $1143,5 \mathrm{Bb}$ & 13,3 & $1090,4 \mathrm{Ba}$ & 13,0 & $7067,2 \mathrm{~b}$ & 7,8 \\
\hline FS-3 & $2722,2 \mathrm{Aa}$ & 10,7 & $2901,5 \mathrm{Aa}$ & 5,7 & $1308,5 \mathrm{Bb}$ & 13,1 & $1158,3 \mathrm{Ba}$ & 10,7 & $8090,5 \mathrm{a}$ & 6,6 \\
\hline
\end{tabular}

Valores de serapilheira seguidos da mesma letra maiúscula na linha e letra minúscula na coluna não diferem estatisticamente entre si pelo teste de Tukey a 5\% de probabilidade; CV = coeficiente de variação.

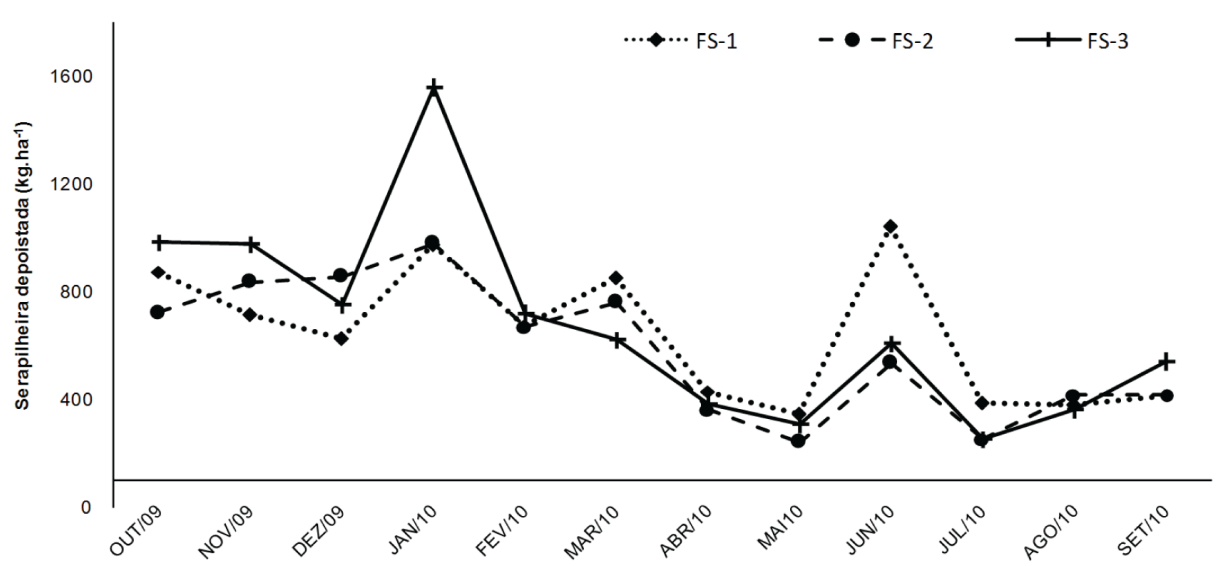

Figura 3. Variação mensal da deposição de serapilheira total em três formações secundárias da Floresta Ombrófila Densa Submontana em Antonina, PR.

Figure 3. Monthly variation of total litterfall in three secondary formations of the Dense Ombrophilous Submontane Forest in Antonina, PR. 
em janeiro de 2010, com maior deposição na FS-3, e o segundo em junho, com maior deposição na FS-1, devido principalmente às folhas de Vochysia bifalcata depositadas no inverno. Nos demais meses, os valores de deposição mostraram-se relativamente próximos, sem uma tendência clara de diferenciação entre as áreas.

De um modo geral, a deposição de serapilheira nas florestas tropicais é contínua, porém variável ao longo do ano (Meguro et al., 1979). Tal padrão se deve à ausência de condições climáticas extremas, como períodos prolongados de frio e seca, aliada à grande diversidade florística dessas florestas (Selle, 2007), com muitas espécies depositando quantidades variáveis de serapilheira. Segundo Silva (1984), as folhas são depositadas em grande quantidade durante todo o ano, com picos pronunciados em certos períodos, que geralmente coincidem com os picos de precipitação. Jackson (1978) sugere que a maior deposição no período chuvoso, que é o mais favorável ao crescimento, seja uma estratégia evolutiva da floresta, pois favoreceria o retorno de nutrientes ao solo e a sua redisponibilização às plantas em crescimento.

$\mathrm{Na}$ Floresta Atlântica, vários autores encontraram o mesmo padrão temporal de maior deposição de serapilheira nos meses de maior precipitação, temperatura e fotoperíodo (Pinto \& Marques, 2003; Araújo et al., 2005; Dickow, 2010; Menezes et al., 2010), sendo essa característica determinante na ciclagem de nutrientes dessas florestas. Em outros ambientes, no entanto, o padrão temporal de deposição de serapilheira tende a ser diferente, uma vez que cada comunidade é composta por muitas espécies, cada uma com diferentes ciclos e respostas ao seu ambiente (Scheer et al., 2009). Aidar \& Joly (2003), estudando plantas de araribá (Centrolobium tomentosum Guillem. ex Benth.) em mata ciliar, encontraram um padrão bimodal de deposição de serapilheira, com os picos de deposição coincidentes com os deste trabalho. Toledo \& Pereira (2004) também verificaram esse padrão em Floresta Estacional Semidecidual, sendo que os autores atribuíram o pico no verão à ação mecânica do vento e da chuva, enquanto que o pico no inverno resultou da perda de órgãos da vegetação, especialmente folhas de espécies decíduas.

A deposição de serapilheira foliar foi significativamente maior do que a deposição das demais frações, seguida pela de ramos, miscelânea e órgãos reprodutivos, em todas as áreas (Tabela 2). No entanto, percebeu-se uma tendência de diminuição na proporção de folhas na serapilheira depositada com o avanço do processo de sucessão secundária (FS-1: 73,6\% da serapilheira total; FS-2: 67,3\%; FS-3: 65,9\%). Esses resultados estão de acordo com vários trabalhos desenvolvidos em florestas tropicais (Martins \& Rodrigues, 1999; Pinto \& Marques, 2003; Toledo \& Pereira, 2004; Pezzatto \& Wisniewski, 2006; Paula et al., 2009; Dickow et al., 2012).

A diminuição da proporção de folhas ao longo do gradiente sucessional pode estar relacionada ao fechamento das copas e sombreamento dos fustes, com consequente maior deposição de ramos como resposta à diminuição de luminosidade nos estratos inferiores da floresta. Além disso, essa diferença na deposição de folhas entre áreas pode estar relacionada à mudança na estrutura da vegetação durante o processo, bem como às características ecológicas das espécies predominantes na vegetação. Segundo Schorn \& Galvão (2006), as espécies apresentam padrões de comportamento, quanto às taxas de ingresso e de mortalidade, de acordo com o grupo ecológico ao qual pertencem e à fase sucessional em que se encontram. Assim, poucas espécies com grande deposição de serapilheira nos estágios iniciais, geralmente pioneiras exigentes em luz, apresentam instalação e crescimento rápidos, mas em espaço de tempo limitado, e são sistematicamente substituídas por várias espécies não pioneiras nos estágios avançados, as quais apresentam crescimento mais lento e contínuo e depositam menores quantidades de serapilheira.

As espécies, em geral, apresentaram diferenças na dinâmica de deposição de serapilheira com o avanço da sucessão secundária. Na FS-1, a deposição de serapilheira foliar foi composta basicamente pelas espécies guaricica (Vochysia bifalcata), jacatirão (Tibouchina pulchra) e tabocuva (Pera glabrata), enquanto que guaricica e a urucurana (Hyeronima alchorneoides) foram as principais espécies responsáveis pela deposição de serapilheira foliar em FS-2 e FS-3.

Em FS-2 e FS-3, houve correlação positiva significativa entre a deposição de serapilheira e a maioria das variáveis meteorológicas do período de estudo, como precipitação, radiação solar e temperatura (média e mínima) (Tabela 3). Ausência de correlação foi verificada entre deposição e temperatura máxima na FS-2, e entre temperatura máxima e umidade do ar na FS-3. Por outro lado, a deposição na FS-1 não 
Tabela 2. Deposição anual de frações de serapilheira e serapilheira foliar por espécie arbórea em três formações secundárias de Floresta Ombrófila Densa Submontana em Antonina, PR.

Table 2. Annual litterfall fractions and leaf litterfall by species in three secondary formations of the Dense Ombrophilous Submontane Forest in Antonina, PR.

\begin{tabular}{|c|c|c|c|}
\hline \multirow{2}{*}{ Frações } & FS-1 & FS-2 & FS-3 \\
\hline & \multicolumn{3}{|c|}{ Serapilheira depositada $\left(\mathrm{kg} \mathrm{ha}^{-1}\right.$ ano $\left.^{-1}\right)$} \\
\hline Folhas (total) & $5684,4 \mathrm{Aa}$ & $4753,9 \mathrm{Ba}$ & $5336,8 \mathrm{Aa}$ \\
\hline Ramos e galhos finos & $768,4 \mathrm{Bbc}$ & $1042,6 \mathrm{ABb}$ & $1235,7 \mathrm{Ab}$ \\
\hline Órgãos reprodutivos & 356,7 Ac & 283,9 Ac & $428,1 \mathrm{Ac}$ \\
\hline Miscelânea & $912,4 \mathrm{Ab}$ & $986,8 \mathrm{Ab}$ & $1089,9 \mathrm{Ab}$ \\
\hline Espécies & \multicolumn{3}{|c|}{ Serapilheira depositada $\left(\mathrm{kg} \mathrm{ha}^{-1} \mathrm{ano}^{-1}\right)$} \\
\hline Vochysia bifalcata Warm. & $1780,6 \mathrm{a}$ & 485,7 a & $547,3 \mathrm{ab}$ \\
\hline Hieronyma alchorneoides Allemão & $267,2 \mathrm{bcd}$ & $351,1 \mathrm{ab}$ & 748,1 a \\
\hline Nectandra oppositifolia Nees & $244,3 \mathrm{bcd}$ & $57,3 \mathrm{c}$ & $190,7 \mathrm{bc}$ \\
\hline Pera glabrata (Schott) Poepp. ex Baill. & $531,0 \mathrm{abc}$ & $51,8 \mathrm{c}$ & $89,4 \mathrm{c}$ \\
\hline Miconia cinerascens Miq. & $154,9 \mathrm{bcd}$ & $212,6 \mathrm{abc}$ & $51,9 \mathrm{c}$ \\
\hline Cupania oblongifolia Mart. & $59,5 \mathrm{~cd}$ & $123,0 \mathrm{bc}$ & $127,0 \mathrm{c}$ \\
\hline Casearia sp. & $43,2 \mathrm{~d}$ & $54,1 \mathrm{c}$ & $124,5 \mathrm{c}$ \\
\hline Tibouchina pulchra Cogn. & $1013,1 \mathrm{ab}$ & - & - \\
\hline Myrsine coriacea (Sw.) R. Br. ex Roem. e Schult. & $56,1 \mathrm{~cd}$ & - & - \\
\hline Alchornea glandulosa Poepp. e Endl. & - & $134,4 \mathrm{bc}$ & $248,0 \mathrm{bc}$ \\
\hline Myrcia pubipetala Miq. & - & $189,2 \mathrm{abc}$ & $61,9 c$ \\
\hline Sloanea guianensis (Aubl.) Benth. & - & $132,5 \mathrm{bc}$ & $97,2 \mathrm{c}$ \\
\hline Matayba guianensis Aubl. & - & $80,7 \mathrm{c}$ & $64,4 \mathrm{c}$ \\
\hline Quiina glazovii Engl. & - & - & $82,6 \mathrm{c}$ \\
\hline Psychotria nuda (Cham. e Schltdl.) Wawra & - & - & $55,4 \mathrm{c}$ \\
\hline Outras espécies & 1534,2 & 2881,5 & 2848,4 \\
\hline Total & 7721,9 & 7067,2 & 8090,5 \\
\hline
\end{tabular}

Valores de serapilheira para as frações seguidos da mesma letra maiúscula na linha e letra minúscula na coluna não diferem estatisticamente entre si pelo teste de Tukey a 5\% de probabilidade; valores de serapilheira para as espécies seguidos da mesma letra minúscula na coluna não diferem estatisticamente entre si pelo teste de Tukey a $5 \%$ de probabilidade.

apresentou correlação significativa com nenhuma variável meteorológica, exceto entre fração miscelânea e precipitação e temperatura (mínima e média). O pico de deposição de serapilheira no mês de junho na FS-1 pode ser resultado de algum fenômeno meteorológico atípico, o qual influenciou na baixa correlação da deposição com os dados meteorológicos. Em síntese, observa-se que as maiores deposições de serapilheira ocorreram nos períodos de maior radiação, maior precipitação e de temperaturas mais elevadas, o que parece ser um padrão para a Floresta Atlântica.

Estudos anteriores realizados na região em outras tipologias florestais encontraram resultados semelhantes em formações florestais do bioma Mata Atlântica. Scoriza \& Piña-Rodrigues (2014) encontraram correlação positiva do aporte de serapilheira com precipitação e temperatura, enquanto Martins \& Rodrigues (1999) encontraram correlação positiva significativa da deposição total de serapilheira com a velocidade média do vento em floresta estacional e correlação negativa significativa com a umidade do ar. Gomes et al. (2006) verificaram que a deposição total de serapilheira de pau-brasil (Caesalpinia echinata Lam.) não apresentou correlação significativa com precipitação, radiação solar ou temperatura, mas observaram correlação significativa positiva com a velocidade do vento e negativa com umidade do ar. Esses dois trabalhos, realizados no interior do estado de São Paulo, indicaram que as maiores deposições de serapilheira ocorreram sob influência do vento.

Diversos estudos realizados em Floresta Atlântica demonstram que as variáveis meteorológicas com maior influência na deposição de serapilheira são a precipitação e a temperatura. Gomes et al. (2010), estudando fragmentos de Floresta Atlântica em Teresópolis, RJ, encontraram correlação positiva 
Tabela 3. Correlação entre as médias mensais das variáveis meteorológicas e a deposição mensal de serapilheira (total e frações) em três formações secundárias de Floresta Ombrófila Densa Submontana em Antonina, PR.

Table 3. Correlation between the monthly averages of meteorological variables and monthly litterfall (total and fractions) in three secondary formations of the Dense Ombrophilous Submontane Forest in Antonina, PR.

\begin{tabular}{|c|c|c|c|c|c|c|c|}
\hline \multirow{2}{*}{ Fração } & \multicolumn{3}{|c|}{ Temperatura } & \multirow{2}{*}{$\begin{array}{c}\text { Precipitação } \\
\text { acumulada }\end{array}$} & \multirow{2}{*}{$\begin{array}{c}\text { Radiação } \\
\text { solar }\end{array}$} & \multirow{2}{*}{$\begin{array}{c}\text { Umidade } \\
\text { do ar }\end{array}$} & \multirow{2}{*}{$\begin{array}{c}\text { Velocidade } \\
\text { do vento }\end{array}$} \\
\hline & Máxima & Média & Mínima & & & & \\
\hline \multicolumn{8}{|c|}{ Floresta Secundária Menos Desenvolvida (FS-1) } \\
\hline Folhas & 0,07 & 0,36 & 0,31 & 0,30 & 0,36 & $-0,30$ & $-0,49$ \\
\hline Ramos & $-0,02$ & $-0,04$ & $-0,17$ & 0,09 & 0,02 & 0,03 & $-0,12$ \\
\hline Órgãos reprodutivos & $-0,24$ & 0,31 & 0,22 & 0,14 & 0,08 & 0,31 & 0,21 \\
\hline Miscelânea & 0,31 & $0,70^{\star *}$ & $0,68^{\star *}$ & $0,74^{* *}$ & 0,65 & $-0,22$ & $-0,32$ \\
\hline Serapilheira total & 0,08 & 0,38 & 0,31 & 0,36 & 0,37 & $-0,22$ & $-0,41$ \\
\hline \multicolumn{8}{|c|}{ Floresta Secundária Intermediária FS-(2) } \\
\hline Folhas & 0,47 & $0,75^{\star *}$ & $0,76^{* *}$ & $0,60^{*}$ & $0,74^{* *}$ & $-0,65^{\star}$ & $-0,50^{*}$ \\
\hline Ramos & 0,27 & 0,28 & 0,23 & 0,42 & 0,47 & $-0,32$ & $-0,43$ \\
\hline Órgãos reprodutivos & 0,15 & $0,66^{\star *}$ & $0,62^{*}$ & 0,38 & $0,63^{*}$ & $-0,37$ & $-0,07$ \\
\hline Miscelânea & 0,50 & $0,85^{\star *}$ & $0,80^{* *}$ & $0,70^{* *}$ & $0,84^{* *}$ & $-0,41$ & $-0,25$ \\
\hline Serapilheira total & 0,47 & $0,76^{\star *}$ & $0,76^{\star *}$ & $0,64^{*}$ & $0,79^{* *}$ & $-0,61^{*}$ & $-0,48$ \\
\hline \multicolumn{8}{|c|}{ Floresta Secundária Mais Desenvolvida (FS-3) } \\
\hline Folhas & 0,35 & $0,57^{\star}$ & $0,61^{*}$ & $0,60^{*}$ & $0,55^{*}$ & $-0,46$ & $-0,52^{*}$ \\
\hline Ramos & 0,22 & $0,54^{*}$ & $0,54^{*}$ & $0,73^{* *}$ & $0,56^{*}$ & $-0,20$ & $-0,61^{*}$ \\
\hline Órgãos reprodutivos & 0,43 & $0,75^{\star \star}$ & $0,76^{\star *}$ & $0,78^{\star *}$ & $0,78^{* *}$ & $-0,42$ & $-0,39$ \\
\hline Miscelânea & 0,24 & $0,63^{*}$ & $0,67^{\star *}$ & $0,77^{\star *}$ & $0,58^{*}$ & $-0,16$ & $-0,48$ \\
\hline Serapilheira total & 0,32 & $0,61^{\star}$ & $0,64^{*}$ & $0,69^{* *}$ & $0,59^{*}$ & $-0,37$ & $-0,55^{\star}$ \\
\hline
\end{tabular}

Teste de correlação de Pearson: * ${ }^{*}$ ignificância a $5 \%$ de probabilidade. ${ }^{* *}$ significância a $1 \%$ de probabilidade.

significativa entre precipitação e deposição de galhos e entre temperatura média máxima e deposição de galhos, material reprodutivo e miscelânea. Abreu et al. (2010) verificaram baixa correlação positiva entre precipitação quinzenal, a deposição de galhos e a serapilheira total em fragmentos florestais na cidade do Rio de Janeiro. Desse modo, a ausência de período com déficit hídrico, aliada à baixa ocorrência de espécies decíduas nesses ambientes, permite uma maior deposição nos períodos de maior precipitação e temperatura.

\section{CONCLUSÕES}

A deposição total de serapilheira variou pouco entre as diferentes formações secundárias da Floresta Atlântica sob estudo, provavelmente devido às pequenas diferenças estruturais entre elas e à proximidade entre as áreas, cuja condição climática é a mesma.

Com relação à sazonalidade, tanto para a serapilheira total quanto para as folhas de algumas espécies e as demais frações, os picos de deposição foram verificados nos meses de maior precipitação e maior temperatura.
A fração folhas foi a mais abundante na serapilheira total nas três áreas. Na FS-1 houve maior deposição de folhas de espécies pioneiras, principalmente Vochysia bifalcata e Tibouchina pulchra. Em FS-2 e FS-3 não houve predomínio de espécie determinada na deposição de serapilheira foliar, o que demonstra participação de um maior número de espécies nesse processo.

\section{STATUS DA SUBMISSÃO}

Recebido: 20 fev., 2015

Aceito: 1 mar., 2016

\section{AUTOR(ES) PARA CORRESPONDÊNCIA}

\section{Jonas Eduardo Bianchin}

Programa de Pós-graduação em Engenharia Florestal, Universidade Federal do Paraná UFPR, Avenida Prefeito Lothário Meissner, 632, Jardim Botânico, Campus III, CEP 80210-170, Curitiba, PR, Brasil e-mail: jonasbianchin@gmail.com 


\section{REFERÊNCIAS}

Abreu JRSP, Oliveira RR, Montezuma RCM. Dinâmica da serapilheira em um trecho de Floresta Atlântica secundária em área urbana do Rio de Janeiro. Pesquisas Botânicas 2010; 61: 279-291.

Aduan RE, Vilela MF, Klink CA. Ciclagem de carbono em ecossistemas terrestres: o caso do Cerrado brasileiro. Planaltina: Embrapa Cerrados; 2003.

Aidar MPM, Joly CA. Dinâmica da produção e decomposição da serapilheira de araribá (Centrolobium tomentosum Guill. ex Benth. - Fabaceae) em uma mata ciliar, Rio Jacaré-Pepira, São Paulo. Revista Brasileira de Botânica 2003; 26(2): 193-202. http://dx.doi.org/10.1590/S010084042003000200007 .

Araújo RS, Piña-Rodrigues FCM, Machado MR, Pereira MG, Frazão FJ. Aporte de serrapilheira e nutrientes ao solo em três modelos de revegetação na Reserva Biológica de Poço das Antas, Silva Jardim, RJ. Floresta e Ambiente 2005; 12(2): 15-21.

Barbosa JHC, Faria SM. Aporte de serrapilheira ao solo em estágio sucessionais florestais na Reserva Biológica de Poço das Antas, Rio de Janeiro, Brasil. Rodriguesia 2006; 57(3): 461-476.

Bertalot MJA, Guerrini EA, Mendoza E, Duboc E, Barreiros RM, Corrêa FM. Retorno de nutrientes ao solo via deposição de serapilheira de quatro espécies leguminosas arbóreas na região de Botucatu-SP. Scientia Forestalis 2004; 65: 219-227.

Bray JR, Gorham E. Litter production in forests of the world. Advances in Ecological Research 1964; 19: 101-157. http://dx.doi.org/10.1016/S0065-2504(08)60331-1.

Calvi GP, Pereira MG, Espíndula A Jr. Produção de serapilheira e aporte de nutrientes em áreas de floresta atlântica em Santa Maria de Jetibá, ES. Ciência Florestal 2009; 19(2): 131-138. http://dx.doi.org/10.5902/19805098404.

Cunha GC, Grendene LA, Durlo MA, Bressan DA. Dinâmica nutricional em Floresta Estacional Decidual com ênfase aos minerais provenientes da deposição da serapilheira. Ciência Florestal 1993; 3(1): 35-64.

Dickow KMC, Marques R, Pinto CB, Höfer H. Produção de serapilheira em diferentes fases sucessionais de uma Floresta Atlântica secundária, em Antonina, PR. Cerne 2012; 18(1): 75-86. http://dx.doi.org/10.1590/S010477602012000100010 .

Dickow KMC. Ciclagem de fitomassa e nutrientes em sucessão secundária na Floresta Atlântica, Antonina, PR [tese]. Curitiba: Setor de Ciências Agrárias, Universidade Federal do Paraná; 2010.

Ferreti AR, Britez RM. A restauração da Floresta Atlântica no litoral do estado do Paraná: os trabalhos da SPVS. In: Galvão APM, Porfírio ES, editores. Restauração florestal: fundamentos e estudos de caso. Colombo: Embrapa Florestas; 2005.

Golley FB, Mcginnis JT, Clements RG, Child GI, Duever MJ. Ciclagem de minerais em um ecossistema de floresta tropical úmida. São Paulo: EPU/EDUSP; 1978.

Gomes JM, Pereira MG, Piña-Rodrigues FCM, Pereira GHA, Gondim FR, Silva EMR. Aporte de serapilheira e de nutrientes em fragmentos florestais da Mata Atlântica, RJ. Revista Brasileira de Ciências Agrárias 2010; 5(3): 383-391. http://dx.doi.org/10.5039/agraria.v5i3a552.

Gomes SR, Maurenza D, Lopes MIMS, Pinto MM. Produção de serapilheira e retorno de nutrientes ao solo em arboreto de pau-brasil (Caesalpinia echinata Lam.) em Mogi-Guaçu, São Paulo, Brasil. Hoehnea 2006; 33(3): 339-347.

Instituto Brasileiro de Geografia e Estatística - IBGE. Manual técnico da vegetação brasileira: sistema fitogeográfico, inventário das formações florestais e campestres, técnicas e manejo de coleções botânicas, procedimentos para mapeamentos. 2nd ed. Rio de Janeiro: IBGE; 2012.

Instituto Paranaense de Desenvolvimento Econômico e Social - IPARDES. Zoneamento da Área de Proteção Ambiental de Guaraqueçaba. Curitiba: IPARDES; 2001.

Jackson JF. Seasonality of flowering and leaf-fall in a Brazilian Subtropical Lower Montane Moist Forest. Biotropica 1978; 10(1): 38-42. http://dx.doi.org/10.2307/2388103.

Kauano EE, Torezan JMD, Cardoso FCG, Marques MCM. Landscape structure in the northern coast of Paraná state, a hotspot for the Brazilian Atlantic forest conservation. Revista Árvore 2012; 36(5): 961-970. http://dx.doi. org/10.1590/S0100-67622012000500018.

Martins SV, Rodrigues RR. Produção de serapilheira em clareiras de uma Floresta Estacional Semidecidual no município de Campinas, SP. Revista Brasileira de Botânica 1999; 22(3): 405-412. http://dx.doi.org/10.1590/S010084041999000300009 .

Meguro M, Vinueza GN, Delitti WBC. Ciclagem de nutrientes minerais na Mata Mesófila secundária. I - Produção e conteúdo de nutrientes minerais do folhedo. Boletim de Botânica da Universidade de São Paulo 1979; 7: 11-31.

Menezes CEG, Pereira MG, Correia MEF, Anjos LHC, Paula RR, Souza ME. Aporte e decomposição de serapilheira e produção de biomassa radicular em floresta com diferentes estágios sucessionais em Pinheiral, RJ. Ciência Florestal 2010; 20(3): 439-452. http://dx.doi.org/10.5902/198050982059.

Paula RR, Pereira MG, Menezes LFT. Aporte de nutrientes e decomposição da serapilheira em três fragmentos florestais periodicamente inundados na Ilha da Marambaia, RJ. Ciência Florestal 2009; 19(2): 139-148. http://dx.doi. org/10.5902/19805098405.

Pezzatto AW, Wisniewski C. Produção de serapilheira em diferentes seres sucessionais da Floresta Estacional 
Semidecidual no oeste do Paraná. Floresta 2006; 36(1): 111-120. http://dx.doi.org/10.5380/rf.v36i1.5596.

Pinto CB, Marques R. Aporte de nutrientes por frações da serapilheira em sucessão ecológica de um ecossistema da Floresta Atlântica. Floresta 2003; 33(3): 257-264.

Ribeiro MC, Metzger JP, Martensen AC, Ponzoni FJ, Hirota MM. The Brazilian Atlantic Forest: How much is left, and how is the remaining forest distributed? Implications for conservation. Biological Conservation 2009; 142(6): 11411153. http://dx.doi.org/10.1016/j.biocon.2009.02.021.

Roderjan CV, Kuniyoshi YS, Galvão F, Hatschbach GG. As unidades fitogeográficas do Estado do Paraná. Ciência \& Ambiente 2002; 24: 75-92.

Scheer MB, Gatti G, Wisniewski C, Mocochinski AY, Cavassani AT, Lorenzetto A et al. Patterns of litter production in a secondary alluvial Atlantic Rain Forest in southern Brazil. Brazilian Journal of Botany 2009; 32(4): 805-817. http://dx.doi.org/10.1590/S0100-84042009000400018.

Schorn LA, Galvão F. Dinâmica da regeneração natural em três estágios sucessionais de uma Floresta Ombrófila Densa em Blumenau, SC. Floresta 2006; 36(1): 59-74. http://dx.doi.org/10.5380/rf.v36i1.5508.
Scoriza RN, Piña-Rodrigues FCM. Influência da precipitação e temperatura do ar na produção de serapilheira em trecho de Floresta Estacional em Sorocaba, SP. Floresta 2014; 44(4): 687-696. http://dx.doi.org/10.5380/rf.v44i4.34274.

Selle GL. Ciclagem de nutrientes em ecossistemas florestais. Bioscience Journal 2007; 23(4): 29-39.

Silva FS, Azevedo CAV. Versão do programa computacional ASSISTAT para o sistema operacional Windows. Revista Brasileira de Produtos Industriais 2002; 4(1): 71-78. http:// dx.doi.org/10.15871/1517-8595/rbpa.v4n1p71-78.

Silva MFF. Produção anual de serapilheira e seu conteúdo mineralógico em mata tropical de terra firme, TucuruíPA. Boletim do Museu Paraense Emílio Goeldi 1984; 1(1-2): 111-158.

Toledo LO, Pereira MG. Dinâmica da deposição de serrapilheira em florestas secundárias do município de Pinheiral, RJ. Floresta e Ambiente 2004; 11(1): 39-46.

Vital ART, Guerrini EA, Franken WK, Fonseca RCB. Produção de serapilheira e ciclagem de nutrientes de uma Floresta Estacional Semidecidual em zona ripária. Revista Árvore 2004; 28(6): 793-800. http://dx.doi.org/10.1590/ S0100-67622004000600004. 